\title{
Italian Studies beyond the Academy
}

\section{Lisa Sampson (University College London) and Daniela Treveri Gennari (Oxford Brookes University)}

\author{
Forthcoming in Italian Studies, 75 (2020)
}

DOI: $10.1080 / 00751634.2020 .1744870$

\begin{abstract}
Over the course of the last decade, considerable emphasis has been placed by public funding bodies on the need to demonstrate the impact of academic research across all subject areas. The article explores the significance of the impact agenda in Italian Studies, primarily in the UK (with reference to the census of impact case studies included in REF2014) but also in Italy and the USA. The article draws some conclusions on best practice, points to new ideas regarding dissemination and impact beyond the academic community, and identifies upcoming challenges which modern languages in general, and Italian Studies in particular, may be facing in the near future.
\end{abstract}

Keywords: impact, Italian studies, public engagement, 'pathways to impact', methodologies, audiences, knowledge exchange

In an increasingly global academic landscape marked by economic, demographic and technological challenges, Italian Studies scholars need to demonstrate the significance and impact - however that is conceived - of their research, or more simply to engage different audiences and stakeholders beyond the academy. In an age characterised by accountability, with growing competition for research budgets, fake news and misinformation campaigns, the notion of the lone scholar in an ivory tower seems both anachronistic and socially irresponsible. Yet, within the Arts and Humanities there is often still some sense of wariness or even perplexity in practice about what exactly constitutes impact; about how best to generate, measure, model and evaluate it; and about what value and recognition impactful activity has, or should have, with respect to 'pure' (or curiosity-driven) research as conceived in the academic context. In some cases there may also be some scepticism about what the real bene fits of impact might be and whether it can be meaningful for all types of research, or if this amounts in some cases to so much box-ticking (or clicking) for the purposes of research monitoring, securing funding or guaranteeing the survival of individual disciplines. Certainly, such questions may be posed less for some disciplines within the broad church of 'Italian Studies', including translation studies, linguistics, economics, or sociological, legal, and political studies. But for others within the arts and humanities, these issues and challenges need to be addressed realistically in order to properly evaluate and articulate the various direct and indirect benefits to society of the research undertaken within the diverse fields of the discipline. The consequences for the future of the field are, after all, too important to ignore.

This article will investigate the significance of impact within the context of Italian Studies by providing some general definitions of the concept as it relates to the field, the 
broader discipline of modern languages and the arts and humanities more generally, as part of a connected interdisciplinary research landscape. We explore the effects of impact with particular reference to the UK, which presents an interesting case in the global research landscape, as one of the first countries to introduce impact as a significant assessment component within its national academic research assessment exercise (Research Excellence Framework, REF). The REF determines the allocation of over£1bnofresearchfundingtoUK universities annually; impact became a criterion of assessment in $2014 .{ }^{1}$ We provide an overview of the impact case studies submitted to the UK REF 2014, with the intention of mapping the landscape, and we highlight some exemplary cases of impact. Diverse examples of impact, public engagement and knowledge exchange activities are presented across Italian Studies, which suggest some of the broader trends and new directions of the research and impactinthe field. ${ }^{2}$ These examples are drawn mostly from the UK context with which we are most familiar, though we also take into account the situation in Italy, the European Research Area and elsewhere; there is insufficient scope here to do more than note the very different linguistic contexts and strategic priorities involved. ${ }^{3}$ Lastly, we provide some thoughts on future opportunities for developing research impact, before concluding by reflecting on the benefits and challenges of the impact agenda within Italian Studies. Though our approach is necessarily selective, we aim to take as inclusive a view of Italian Studies as possible, drawing especially on cases documented in public research data and by public research funding bodies in the arts and humanities.

\section{Italian Studies: The UK Context and the Impact Agenda}

In the case of the United Kingdom, the impact of Italian Studies research (understood here as research into language, linguistics, and language-based cultural and area studies) has to be considered within the context of modern languages as a whole and the sustainability of the discipline. The UK has, since around the turn of the millennium, seen a downturn overall in 60take-up in post-primary level schools (from age eleven), especially since the sharp decline after 2002, when foreign languages stopped being a compulsory element in the school curriculum up to the age of sixteen (GCSE). This situation has been compounded in part by the fact that modern languages are negatively perceived as being difficult and a risky exam choice, elitist and for the privileged few, or irrelevant when 'the world speaks English these

\footnotetext{
${ }^{1}$ Molly Morgan Jones, Catriona Manville, and Joanna Chataway, 'Learning from the UK's Research Impact Assessment Exercise: A Case Study of a Retrospective Impact Assessment Exercise and Question for the Future', Journal of Technology Transfer, 38.5 (2017), 1-25, p. 7. However, in 2013 only $3 \%$ of the annual total UK research council spend went to the Arts and Humanities Research Council (AHRC) and 6\% to the Economic and Social Research Council (EHRC). See David Cope, 'The Impact School...of Driving, that is... (or The Strategic Importance of Impact)', in 7 Essays on Impact. DESCRIBE Project Report for Jisc, ed. by Andrew Dean et al., University of Exeter (2013), pp. 4-13 (p. 5).

${ }^{2}$ For the purpose of this article we have decided to focus mainly on the term 'public engagement' and not the broader concept of 'knowledge exchange'. This is because we believe it more appropriate for the context of the research we have conducted, since the remit of public engagement more specifically refers to activities of engagement with anybody not previously involved in the research, while KE includes those already connected with the research, such as for example, stakeholders from the industrial, commercial, and public sectors. Our investigation within Modern Languages - and Italian Studies in particular - makes public engagement a more pertinent definition. Moreover, KE is still being shaped as a concept, specifically in the humanities. See Simon Moreton, 'Rethinking "Knowledge Exchange": New Approaches to Collaborative Work in the Arts and Humanities', International Journal of Cultural Policy, 22.1 (2016), 100-15.

${ }^{3}$ For an overview of the impact context in Germany, France and the Netherlands, see Anke Reinhardt, 'Different Pathways to Impact? "Impact” and Research Fund Allocation in Selected European Countries', in 7 Essays on Impact, pp. 88-101.
} 
days (or should)'. The fact that fewer languages are studied now by fewer students in state secondary schools up to age sixteen has had a serious effect at university level in recent years. ${ }^{4}$ Modern languages provision has correspondingly been scaled back or cut altogether as an academic subject in some Higher Education Institutions (HEIs), including those from the shrinking number where Italian Studies is still taught as an undergraduate degree. ${ }^{5}$ In the face of this language deficit, the UK may potentially encounter more challenges in the context of Brexit, when it may be able to rely less on native speakers, including school teachers and university staff, and on EU student exchange programmes like Erasmus. ${ }^{6} \mathrm{~A}$ report commissioned in 2017 by The British Council in the wake of the Brexit referendum argues that investment in the discipline of modern languages as a whole is critical in 'a new era of cooperation with Europe and with the rest of the world ', to upgrade 'the UK's ability to understand and engage with people internationally'. The reasons are not only economic; there are also important considerations relating to trust and the need both to 'deepen international influence and cultural relationships, and to keep our country safe'.

These issues surrounding the health of modern languages in the UK have been addressed in recent years through a variety of initiatives and institutional responses, which have placed emphasis on, among other things, the social importance of language and intercultural studies. ${ }^{8}$ These initiatives have begun to prompt a broader critical reflection and reevaluation of the purposes of language learning and inter-cultural education, which in turn resonate with broader questions relating to the value and impact of associated research fields. A stimulus to this was the multimillion-pound Open World Research Initiative (OWRI)

\footnotetext{
${ }^{4}$ See The British Council's 'Language Trends 2018' report and the recent BBC survey of secondary school language provision (27 February 2019): <https://www.bbc.co.uk/news/education-47334374> [accessed 11 April 2019]. The take-up of modern languagesatGCSEdroppedfromc. $75 \%$ in 2002 to $40 \%$ in 2011 but increased to $49 \%$ in 2014withtheintroduction of the English Baccalaureate. French and German have seen the steepest decline, while Spanish and Mandarin have gained in popularity. Italian language is rarely taught at school level, though the BBC report shows numbers taking Italian GCSE have risen by over 10\% since 2013. Figures for language uptake vary according to geography (take-up is higher in London, though Welsh is compulsory in Wales until age sixteen) and gender (a higher proportion of girls study languages), with far higher take-up in private schools. See <https://www.britishcouncil.org/voices-magazine/teenagers-in-england-less-likely-to-learn-languages $\geq$ [accessed 7 March 2019]; and Patterns and Trends in UK Higher Education 2018, p. 20 <https://www.universitiesuk.ac.uk/ facts-and-stats/data-and-analysis/Documents/patterns-and-trends-in-ukhigher-education-2018.pdf> [accessed 14 April 2019].

${ }^{5}$ Of particular note here is the sad announcement in 2019 of the closure of Italian Studies at the University of Hull, with staff 'teaching out' existing years of students.

${ }^{6}$ Humanities and language-based studies and archaeology have had the highest or second highest percentage of EU staff of all cost centres in UK universities (from 18\% in 2006-07 to $23 \%$ in 2016-17), Patterns and Trends in UK Higher Education 2018, 'Academic staff by nationality and cost centre, 2006-07 to 2015-16', p. 27 (Table 9). On the challenges to modern languages posed by Brexit, see the British Council report Languages for the Future (November 2017): <https://www.britishcouncil.org/ organisation/policy-insight-research/languagesfuture-2017>; and the article by Alice Campbell-Cree (14 November 2017):

$<$ https://www.britishcouncil.org/voices-magazine/which-foreign-languages-will-be-most-important-uk-postbrexit> [both websites accessed 19 July 2019].

${ }^{7}<$ https://www.britishcouncil.org/sites/default/files/languages_for_the_future_2017.pdf. See also the British Academy report 'Lost for Words: The Need for Languages in UK Diplomacy and Security' (November 2013) <https://www.thebritishacademy.ac.uk/ publications/lost-words-need-languages-uk-diplomacy-and-security> [accessed 11 April 2019].

${ }^{8}$ The University Council for Modern Languages (UK) provides an overarching national body representing the discipline. The programme 'Routes into Languages' is no longer funded, but school-level activities at a regional level are co-ordinated by the University of Southampton (<https://www.routesintolanguages.ac.uk> [accessed 14 April 2019]). Language learning is currently compulsory at primary level in most parts of the UK but not Northern Ireland.
} 
announced in 2014 by the UK Arts and Humanities Research Council (AHRC). The aim was to 'establish a new and exciting vision for languages research in response to the challenges and opportunities presented by a globalised research environment and multi-lingual world'. The four selected programmes (2016-20) are all multi-institutional, highly interdisciplinary and emphatically multi-lingual, though Iberian languages are the specific focus in one. They pursue research that is rooted in language and intercultural issues alongside an enormous range of activities designed to engage different kinds of audiences beyond academia, including schools and grass-roots communities across the UK and world-wide. These activities range from public lectures, exhibitions, debates, and events in classrooms, to fieldwork among diasporic communities, and theatre and musical events. ${ }^{10}$

Further initiatives to enhance capacity building and the UK's research capability in languages include the appointment of an AHRC Modern Languages Leadership Fellow to oversee these programmes and to enable political advocacy for the discipline as a whole. ${ }^{11}$ The British Academy also specifically promotes modern language skills (alongside quantitative skills) to counter what has been termed a 'vicious cycle of monolingualism'. ${ }^{12}$ This institution has a particular commitment to cross-disciplinary research and enquiry involving languages (including their use in the creative arts) and bridging Britain, Europe, the Commonwealth and beyond. Its particular links with Italy are sustained through the wideranging and exciting work of the British School at Rome.

Turning to Italian Studies more specifically, despite the shrinking of publicly funded language learning, a strong case can be made for its promotion within the particular context of the UK and its potential for impact and public engagement. While Italian is not a 'global language' like Spanish, Mandarin, French, and Arabic, it has been ranked as the sixth most important language (after German) for the UK's prosperity in The British Council's 2017 'Languages for the Future' report. ${ }^{13}$ Furthermore, Italian culture - spanning popular and 'high' culture - holds a strong sway. As the cases discussed below show, this has enabled research in Italian Studies to have an impact on many different sectors and disciplines. What emerges most conspicuously overall is the creativity and diversity of impact resulting from research by individuals or collectives, often - but not always - as part of funded projects. These have frequently involved fruitful multidisciplinary collaborations and in turn generated new insights for ongoing research. However, there is a concern by academics that the impact generated by research in Italian Studies - and the humanities more broadly - may often take 'softer' forms with intangible benefits that are harder to measure and audit. They may, for instance, affect targeted audiences from minorities or areas of deprivation, and the benefits to society may only be felt in the longer-term. Moreover, it is feared that the impact agenda

\footnotetext{
${ }^{9}$ On the OWRI initiative ( $£ 15$ million) and the four major collaborative research projects supported by this scheme see: https:// ahrc.ukri.org/research/funded themes and programmes/themes/owri/ [accessed 9 April 2019]. The original funding call budgeted $£ 20$ million for five projects.

${ }^{10}$ An example is the multilingual song by Lin Marsh sung in seven languages (not including Italian) by five hundred local school children in the Oxford Festival of the Arts. See <https://www.creativeml.ox.ac.uk/blog/exploring-multilingualism/we-arechildren-world-27-june-2018> [accessed 14 April 2019].

11 <https://www.modernlanguagesleadershipfellow.com/> [accessed 11 April 2019].

12 Teresa Tinsley, 'Languages: The State of the Nation' (2013):

$<$ https://www.thebritishacademy.ac.uk/publications/languagesstate-nation> [accessed 9 April 2019].

$13<\mathrm{https}$ //www.britishcouncil.org/sites/default/files/languages_for_the_future_2017.pdf $>$ Italian appears above Dutch, Portuguese, Japanese, and Russian.
} 
within publicly funded research risks distorting the emphases and processes of academic research in Italian Studies by increasingly privileging applied research or research in fields that lend themselves more readily to public engagement. A further charge is that the impact agenda may lead to 'an outcome-led evaluation of the humanities', which undermines the processes critical to humanities research - a charge also made in some areas of the sciences. ${ }^{14}$ There is, additionally, a deeper concern that the ultimate measure for research is shifting from academic quality and knowledge production to the number of 'external research users and the range of impact indicators'. ${ }^{15}$ These are issues which need to be weighed up in light of the future of the discipline.

\section{'Impact': Some Definitions}

In trying to present an overview of the ways in which the impact agenda has altered the shape and focus of Italian Studies research, one faces a number of difficulties: how to define 'impact' - for instance, how to distinguish it from 'public engagement' and 'knowledge exchange'-bearing in mind the differences between national contexts; how to pin down what is (and is not) included in or attributed to Italian Studies; and, more practically, how to categorise and do justice to the plethora of successful examples for the purposes of this survey? This last point involves acknowledging the necessarily selective and partial way that case studies (including those of the present authors) have been reported across a variety of fragmented platforms and come to public and scholarly attention.

Impact was formally introduced to the UK Research Excellence Framework in REF2014, where it was defined as an 'effect on, change or benefit to the economy, society, culture, public policy or services, health, the environment or quality of life, beyond academia'. The discussion had already started five years earlier when the Higher Education Funding Council for England (HEFCE) had set out a number of principles for assessing research impact. They proposed to assess impact predominantly on the basis of a relatively small number of 'case studies', which 'should carry a weighting of twenty-five per cent within the overall assessment', with twenty-nine HEIs making submissions to five pilot panels. ${ }^{16}$ Quite rapidly, the impetus for academic research to have an impact on society and the economy was formally set out, and UK public funding bodies began to introduce an impact category to their application systems. The UK Research and Innovation (UKRI) website provides a definition of 'Pathways to Impact' to help academics determine precise strategies to ensure research can make a difference beyond the academic community. This suggests that a 'clearly thought through and acceptable Pathways to Impact is an essential component of a research proposal and a condition of funding'. ${ }^{17}$ Any researcher intending to

\footnotetext{
${ }^{14}$ Zoe Bulaitis, 'Measuring Impact in the Humanities: Learning from Accountability and Economics in a Contemporary History of Cultural Value', Palgrave Communications, 3 (2017), 1-10; Cope, 'The Impact School'.

15 Bulaitis, p. 3.

${ }^{16}$ Decisions on assessing research impact, REF 2014, RKTC 110315/22: https://www.ref.ac.uk/2014/media/ref/content/pub/decisionsonassessingresearchimpact/01_11.pdf [accessed 12 May 2019]. The actual weighting of impact in REF 2014 was $20 \%$, increased to $25 \%$ for REF 2021. The number of impact cases submitted for REF2021 will depend on the number of staff submitted, and ranges from 2 to 10 (for160 or more staff, plus one further case study per additional $50 \mathrm{FTE}$ ): $<$ https://www.ref.ac. uk/media/1016/draft-guidance-on-submissions-ref-2018_1.pdf> (pp. 86-87) [accessed 14 April 2019]. 17 <https://www.ukri.org/innovation/excellence-with-impact/pathways-to-impact> [accessed 16 April 2019]. A statement issued in early2020 (as this article was being finalised) announced UKRI's intention to withdraw the 'Pathways to Impact' requirement for future research grants. As explained by UKRI, the withdrawal provides
} 
apply for funding through the Research Councils has to outline how the project aims to engage with external partners, local communities and organisations which become the nonacademic beneficiaries of the research findings. In this way, public research is clearly framed within a discourse based on business and management models which corresponds to an increased marketisation and instrumentalization of research. As noted by Zoe Bulaitis, this has been operating within the university sector since $2010 .{ }^{18}$ The AHRC has also been trying to stimulate research impact further by introducing the Follow-on Funding for Impact and Engagement Scheme to generate impact from previously funded projects. This call 'provides funds to support innovative and creative engagements with new audiences and user communities which stimulate pathways to impact' through a series of targeted activities, which allow the effects of the research to be monitored and measured. ${ }^{19}$

The idea of 'impact' is therefore closely related to the concept of knowledge exchange, which generally implies engagement with a range of audiences or stakeholders from outside academia to develop and communicate underpinning research. It implies collaboration with 'public, private and third sector partners' which produces some sort of transformation - a measurable impact with tangible benefits. ${ }^{20}$ However, this opens up various questions as to what this 'transformation' may be for (e.g. education, community building, heritage preservation, or to stimulate general interest and awareness) and how it can be measured or evaluated - especially in the humanities where the emphasis is more on qualitative as opposed to quantitative reasoning, and on individualistic rather than collective responses. Further, there is an issue of timing: at what stage of the research process can and should impact be planned for, generated, and how long after the original research has been undertaken can it have impact - when is the best stage to measure impact, given that it is cumulative over time? Finally, there is the question of how to communicate research findings most effectively - what elements can and should be communicated, and to whom? For all these questions, evidence suggests there are no hard and fast rules in practice. However, specific criteria have been set out by the REF, which awards public funding to HEIs on the basis of measurable research excellence. ${ }^{21}$ These criteria increasingly direct and channel the research impact agenda. The subsequent monitoring of results from funding has also contributed to standardising and collecting longitudinal data on impact, following metrics modelled on the sciences. ${ }^{22}$ Meanwhile, HEIs, other research institutions and individual researchers have increasingly embraced public engagement and are due to be nationally

recognition that impact is now embedded in the research agenda and that 'Pathways to Impact has been important in driving a culture change [so that] the requirement to capture this in a separate section is no longer needed'. See https://www.ukri.org/news/pathways-to-impact-impact-core-to-the-ukresearch-and-innovationapplication-process/ [accessed 20 February 2020].

18 Bulaitis, p. 3.

19 <https://ahrc.ukri.org/funding/apply-for-funding/current-opportunities/followonfunding/> [accessed 16 April 2019].

${ }^{20}$ See <https://ahrc.ukri.org/innovation/knowledgeexchange/> [accessed 23 January 2020].

${ }^{21}$ In the UK, $15 \%$ of the total income received from mixed sources by universities comes from government grants for research, while universities spend collectively $56.6 \%$ of their income on teaching and research. See <https://www.universitiesuk.ac.uk/ facts-and-stats/Documents/university-spending-explained-summary.pdf> [accessed 14 May 2019].

${ }^{22}$ For example, many research funders (including all the UK research councils, and some NGOs) use Researchfish, a Research Impact Assessment platform launched in 2012 (based on an existing platform designed in 2008-09 to meet the needs of the UK Medical Research Council). This aims to 'standardis[e], simplif[y] and enhance[e] research impact assessment to enable better research decisions to be made by funders, research institutes and researchers across the world' (<https://www.researchfish.net/> [accessed 11 April 2019]). 
benchmarked on strategies for Knowledge Exchange. ${ }^{23}$ This may push the impact agenda in different directions and for different purposes, reflecting awareness of community and 'citizenship' responsibilities, and the mutual benefits of collaborating with a range of stakeholders.

In the UK the relative weight given to impact in research assessment has increased slightly since 2014, rising from $20 \%$ to $25 \%$ of the allocation for REF2021. While the definition of impact has not changed since its introduction in the REF2014, a new set of criteria has been published, which addresses concerns raised about the REF2014 and introduces changes to the areas eligible for submission for REF2021. These include, for instance, impacts 'on teaching within, as well as beyond, the submitting institution'. ${ }^{24}$ The definition of impact has therefore been refined and expanded, and lessons have been learned about effective evaluation of impact. However, a researcher in the UK may now struggle to secure external funding for a project that does not envisage impact. The Leverhulme Trust is an unusual example of a funding body that has not embraced impact through its funding procedures or its public workshops. Its approach contrasts sharply with, for instance, that of the Wellcome Trust, which pays close attention to public engagement and impact throughout its funding schemes and reports. ${ }^{25}$

The situation in Italy is very different. Firstly, within the academic sphere there is much less attention given to the impact that research can have, especially in the context of the humanities. Formal applications to research funding bodies such as the PRIN (Progetti di Rilevante Interesse Nazionale) exclude any reference to impact or pathways to impact. When a project wins funding, investigators are asked to comment on whether 'Collaboration agreements with national or international companies' have been activated, but this seems to apply more to projects in the sciences than in the humanities. ${ }^{26}$ Even so, impact-perhaps not explicitly defined as such - is key in practice to attracting mixed forms of sponsorship for research, especially at a local and regional level, for example from banks and businesses. The engagement of stakeholders and evidence of meaningful impact, therefore, may take place in a more organic and spontaneous way. Mantua's Fondazione di Palazzo Te, founded in 1990, provides an exemplary model for how research and impact can be mutually reinforcing. It brings together a variety of stakeholders with the aim of providing public (Comune di Mantova) and private funding, including for longer-term academic research projects addressing the city's vast cultural heritage (especially its outstanding art collections, architecture, and archives). ${ }^{27}$ The Fondazione also hosts a vast range of multi-disciplinary activities, to provide financial sustainability; these include conferences, publications, public exhibitions (over fifty since its inauguration) and, since 2018, a programme of educational activities for schools (Scuola di Palazzo Te). Of special interest to the early modern scholarly community is its centralised and freely accessible database I Gonzaga digitali, Banche dati

\footnotetext{
${ }^{23}$ On the Knowledge Exchange Framework (KEF) assessment, which is less directly linked to research than REF, see: https://re.ukri. org/knowledge-exchange/knowledge-exchange-framework/ [accessed 15 January 2020].

${ }^{24}$ Draft guidance on submissions, REF 18/01, July 2018.

${ }^{25}$ See <https://wellcome.ac.uk/funding/schemes/public-engagement-fund> [accessed 8 January 2020]; $<$ https://wellcome.ac.uk/sites/default/files/wtp052364_0.pdf $>$ [accessed 8 January 2020].

26 <http://www.prin.miur.it/> [accessed 23 July 2019].

${ }^{27}$ For information, see the 'Chi siamo' section: <https://www.centropalazzote.it/> [accessed 19 April 2019].
} 
per la ricerca Gonzaga, which integrates four important digital archives linked to high-

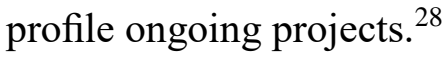

The EU offers a mixed mode of research funding, which does not necessarily place a requirement on impact. Horizon 2020 projects are expected to be linked with 'real world' concerns. The call most relevant to researchers in Italian Studies, 'Europe in a changing world - Inclusive, innovative and reflective societies', isolates 'memories, identities, tolerance and cultural heritage' in order to address major challenges associated with migration, socioeconomic and cultural transformations in the context of the fourth industrial (digital) revolution, and governance. ${ }^{29}$ In contrast, the European Research Council (ERC) frontier research grants, which are awarded to individual researchers leading teams, explicitly make 'scientific excellence' the sole criterion for an award, without the need to build in pathways to impact during the project. $^{30}$

In the United States the National Endowment for the Humanities (NEH) budget has more than halved since 1980 and federal, state and private funding has all been reduced for the humanities. ${ }^{31}$ However, the Andrew W. Mellon Foundation has as its mission 'to strengthen, promote, and defend the centrality of the humanities and the arts to human flourishing and to the wellbeing of diverse, fair, and democratic societies'. It funds a wide range of research grants with the aim of extending the benefits of higher education to all students, through support for diversity and inclusiveness in its programmes. These are often US-focused, but also involve global collaborations and impact. The Foundation's activities are underpinned by a belief that HEIs 'produce, preserve, and transmit [knowledge and innovative research] for the good of culture and society', and that a 'liberal' humanities education will enable key debate on contemporary social challenges and political issues. ${ }^{32}$ Research projects funded by the Foundation therefore involve various forms of outreach to enable access to education by grass-roots communities, via institutional pathways or digital platforms. These examples demonstrate how open access of research has become increasingly important for a number of international funding bodies, as a way to enable pathways to impact, although outcomes may not be a specific criterion for evaluation or allocation of funding.

\section{The Effects of the Impact Agenda on Italian Studies}

What are the effects of the impact agenda on the humanities in general and Italian Studies in particular? Is there a danger that the increased concern with impact and changes to funding

\footnotetext{
${ }^{28}$ The database project is ongoing and includes records on the Archivio Gonzaga (1328-1707) from four projects collected since 1998, see <http://banchedatigonzaga.centropalazzote.it/portale/> [accessed 14 April 2019].

29 The 'Europe in a Changing World' Work Programme 2018-2020 can be accessed via: <https://ec.europa.eu/programmes/ horizon2020/en/h2020-section/europe-changing-world-inclusive-innovativeand-reflective-societies> [accessed 14 April 2019].

${ }^{30}$ The question of 'potential impact' is, however, to be addressed in the 'scientific proposal' and enabled through making all peer reviewed publications arising from ERC projects Open Access (online, free of charge) and open to data-sharing where possible. See <https://erc.europa.eu/funding/advanced-grants> [accessed 14 April 2019].

${ }^{31}$ IV-1b: National Endowment for the Humanities Funding, by Purpose, Fiscal Years 1966-2018 (Adjusted for Inflation): https:// www.humanitiesindicators.org/content/indicatorDoc.aspx?i=75 [accessed 13 April 2019]. 32 <https://mellon.org/programs/higher-education-and-scholarship-humanities/> [accessed 14 April 2019].
} 
models will skew the overall research landscape or at least the picture that emerges thereof? Will it exclude more 'traditional' forms of studies based on 'pure' research, destined primarily for academic audiences in specialised fields?

Undoubtedly, there are specific research areas and projects within the humanities that lend themselves more readily to wider communication and generating impact. This may be because they tap into existing areas of interest stimulated by television, film and social media - as is the case, for example, with ongoing studies on the mafia and organised crime, fascism, iconic figures like Dante, the Medici, Mussolini, or food, football, cycling, art, cinema, and fashion. Inevitably, discoveries of new Italian voices and works (like Elena Ferrante's Neapolitan Novels) and popular genres like detective fiction will also excite public attention, especially if translated and brought to popular attention through television, film and social media. ${ }^{33}$ Yet, as is clear from the analysis of the examples presented below, subject matter and period do not necessarily prevent new research on less familiar subjects from generating impact, especially when the project design builds in creative ways of developing pathways to impact, often involving collaborations with external partners, from the very outset.

A more significant difficulty in terms of the 'impact agenda' envisaged by the REF is the fact that the majority of research projects in the humanities (and to a lesser extent the social sciences) do not readily generate measurable impact. It can be challenging to demonstrate that the research findings of a project in literature, art, or film studies alter the activity, attitude, or behaviour of an audience, beneficiary, community, organisation or individuals, locally, regionally, nationally or internationally. Creative solutions for modelling knowledge translation processes and gathering evidence to create a narrative of impact for REF must also be put in place or sought out retrospectively. ${ }^{34}$ This places an additional time burden on individual researchers contributing case studies for their institutions. ${ }^{35}$ While official REF guidelines provide reassurance that impact will be assessed in relation to the success of the project in reaching potential constituencies or beneficiaries, rather than in relation to the geographic extent of the impact or the absolute number of beneficiaries, such impact often remains more difficult to evidence in the humanities than in the sciences. ${ }^{36}$ Particular difficulties in assessing impact in the arts and humanities (and modern languages especially) compared to other academic disciplines include a longer time-lag in registering impact, ${ }^{37}$ the non-linearity of the relationship between research and its impact, and tensions between the nature of the research and impact metrology. Against that backdrop, what one notices about Italian Studies is a readiness by many academics to branch outside what were considered core fields and to take their research in a wide variety of directions, involving comparative or interdisciplinary approaches and collaborative multi-national partnerships, which might lead to a more substantial and measurable impact, especially when working with stakeholders outside academia. As we will see, Italian Studies is well represented in

\footnotetext{
${ }^{33}$ On the event 'Ferrante Fever' at the University of Leeds (2016), see https://ahc.leeds.ac.uk/livitaly-bringingitalian-cultureyorkshire/doc/ferrante-fever> [accessed 8 May 2019].

${ }^{34}$ B. Belcher, D. Suryadarma, and A. Halimanjaya, 'Evaluating Policy-Relevant Research: Lessons from a Series of Theory-based Outcomes Assessments', Palgrave Communications 3, article 17017 (2017).

35 The burden to prepare impact submission for REF2014 was estimated on average $£ 55 \mathrm{~m}$ per university and each case study cost an estimated $£ 7500$. See Morgan Jones, Manville and Chataway, p. 13.

${ }^{36}$ King's College London and Digital Science, The Nature, Scale and Beneficiaries of Research Impact: An Initial Analysis of Research Excellence Framework (REF) 2014 Impact Case Studies (HEFCE: Bristol, 2015), p. 59.

${ }^{37}$ The Nature, Scale and Beneficiaries of Research Impact, p. 45.
} 
successful grant applications with impact elements, across all periods and fields. Though based on a 'minor' language, the discipline contributes considerably to growing international fields like translation and reception studies, migration and network studies, and studies involving Italy as part of Mediterranean and European cultures. Such participation increases the potential for research impact.

\section{Overview of Impact Case Studies in Italian from REF2014}

For an initial snapshot of 'impact' in Italian Studies five years after this was formally introduced, a search using the word 'Italian' on the REF 2014 website revealed 288 Impact Case Studies (out of 1,561 in Modern Languages -within which Italian was not individually highlighted). ${ }^{38}$ However, several of these impact cases were outside the remit of this survey and of what we understand here as the discipline of Italian Studies, as they ranged from Computer Science and Informatics, Earth Systems and Environmental Sciences, Physics, Economics and Medical Science. We have narrowed the focus to the following areas: Modern Languages (fifteen cases), Music, Drama, Dance and Performing Arts (seven), History (five), Classics (four), Art and Design (three), Communication, Culture and Media Studies (one).

A close analysis of the impact cases submitted under these specific Units of Assessment illustrates the variety of subjects, methodological approaches and public engagement activities that have developed under the broad umbrella of Italian Studies. Within the areas researched, alongside textual and contextual analysis of classic authors (two projects on Dante and the political, religious and intellectual practice of late medieval Italy, for example), are two projects on Mussolini (a multi-faceted investigation of the genesis, functioning and decline of the personality cult of the Italian dictator; and an attempt to better understand of fascism and its legacy by challenging preconceptions about Mussolini and examining the legacy of his leadership 'cult' in Italy and beyond); three projects on cinema (two on audiences and one on music and film); six projects on cultural heritage, exhibition and museum studies; two on gender, of which one on Italian women and the other on public awareness of issues affecting LGBTQ communities and cultures in Italy; three on music (specifically, the reception of Puccini's operas, a new critical edition of Donizetti's Le Duc d'Albe and the Musica Secreta ensemble and its amateur choir Celestial Sirens); two on linguistic research, translation and its impact on the community; two on language and identity; and one project on the issue of authenticity in the work of Leonardo da Vinci.

The wide range of research topics from the Medieval period to contemporary times is matched by a correspondingly broad range of methodologies and impact activities. Some projects have included video recordings of their lectures and talks and made them available on their websites in order to extend the geographical reach of their impact. Others have organised events where the public is invited to reflect on and engage with aspects of the research. Several projects have generated online resources, which vary from policy documents to pedagogical activities for adult learners and secondary school students. Performances and art exhibitions are deployed to introduce little-known anti-Fascist artworks

\footnotetext{
$38<$ https://impact.ref.ac.uk/casestudies> [accessed 23 April 2019]. For a breakdown of categories of impact involving the Arts and Humanities in REF2014, which broadly reflect the trends in Italian Studies, see The Nature, Scale and Beneficiaries of Research Impact, p. 33 (Figure 8) and p. 35 (Figure 10).
} 
to British audiences, illustrating the importance of manipulating visual imagery for political authority. ${ }^{39}$ Other projects improve public understanding and appreciation of European cinema nationally and internationally, by contributing to online archival studies of cinema audiences, participation in film festivals, introductions to film screenings, public lectures and DVD commentaries. In order to improve public understanding of right-wing populism, one impact case study explores how journalists and policy makers have interpreted the success and characteristics of the phenomenon in Europe. ${ }^{40}$ This is undertaken with the intention of increasing awareness within the Italian legal system - specifically among barristers and judges - to the point of shaping the practice of interviewing witnesses in the country.

Some projects take advantage of close collaboration with a range of contributors and stakeholders outside academia, which may require new methodologies and types of research activity. Distinct groups of the public may be included in the impact: the elderly are engaged in reconstructing the history of significant moments in Italian film industry; the LGBTQ community are supported in meeting societal challenges and thereby improving their wellbeing; discrete sections of the public are made aware of the politics of sexuality and gender. Beneficiaries also include specialised categories, such as cine-enthusiasts, those interested in musicals, for example, and those who want to be better informed about the significance of individual areas of research. Research projects also contribute to the teaching of a wide range of subjects (from cinema to history), to the enhancement of cultural life and to teaching in secondary schools and HEIs.

Such impact can be achieved through the dissemination of an individual scholar's work, especially when it maps onto areas of contemporary interest, by engaging public attention via commercial publishers, television, radio and the press. Historical research on nation building and Fascism has contributed to intense political and media debates about Italy's 'national identity', especially fuelled by the recent political and economic crisis. ${ }^{41}$ Other research on the Italian mafia, camorra, and 'ndrangheta, combining archival discoveries and a new comparative synthesis of existing studies, formed the basis for three very successful publications from 2004 to 2013, which produced impact in various sectors through their international diffusion. ${ }^{42}$ This research influenced the professional preparation and development of law enforcement officers and judiciary services engaged in front-line work against the mafias. It has also informed media discourses on the mafia, through extensive coverage on international radio, TV and websites, as well as the author's presentations to news professionals. John Dickie's book Cosa Nostra (2004) specifically changed the behaviour of local communities and the travel industry. It was used as a point of reference by the Sicilian anti-mafia organisation Addiopizzo, 'which takes a revolutionary approach to

\footnotetext{
39 'The Cult of the Duce: Visual Imagery and Built Heritage of Italian Fascism':

$<$ https://impact.ref.ac.uk/casestudies/CaseStudy.aspx? Id=7372> [accessed 20 May 2019].

40 Ibid.

${ }^{41}$ See the impact of Christopher Duggan's numerous works in the field, which include the immensely popular The Force of Destiny: A History of Italy since 1796 (London: Allen Lane, 2007); the first edition (6,000 in hardback) sold out in six weeks.

${ }^{42}$ All by John Dickie: Cosa Nostra: A History of the Sicilian Mafia (London: Hodder \& Stoughton, 2004); Mafia Brotherhoods: Mafia, Camorra, 'Ndrangheta: The Rise of the Honoured Societies (London: Sceptre, 2011); Mafia Republic (London: Hodder \& Stoughton, 2013). Cosa Nostra had by 2014 appeared in twenty-one languages plus Braille; by Spring 2011 it had sold 750,000 copies worldwide. The book's yearly English language sales (excluding the US market) from 2008 to 2011 exceeded 60,000, with sales peaking in 2008 $(16,371)$ and $2011(16,465)$.
} 
fighting the mafia by bringing together businesses that refuse to pay protection money to Cosa Nostra with consumers', including tourists. ${ }^{43}$ Furthermore, the book became the basis of the government-funded programme of education about the mafia for secondary school students. As the REF2014 impact case study notes, the book's impact was considerably enhanced by being 'written for non-specialist audiences, presenting both original and established research to a global audience in an accessible while still academically rigorous manner'; that fact and the compelling narrative also explains the great number of translations. The case reminds us of the need to create an appropriate style for communicating with largescale audiences in order to achieve broader social transformations.

On the other hand, several projects with significant impact make use of collaboration and develop a team-based research model involving multi-disciplinary partners. This approach - already well established in the social sciences - offers the potential to develop combined, cutting-edge methodologies, while expanding the scope of research far beyond what a single author could achieve. Multidisciplinary, collaborative projects with stakeholders from outside academia, and which build in pathways to impact from the outset, have the potential to develop new methodologies and theoretical frameworks. An example of this is the well-established Knowledge Transfer Partnership programme, which has been supporting businesses 'to improve their competitiveness and productivity through the better use of knowledge, technology and skills'. ${ }^{44}$ Such forms of collaboration may respond to new research enquiries and discoveries and/or to perceived social interest, demands and opportunities, which in turn stimulate the research process in a circular rather than linear fashion.

\section{New 'Impactful' Directions in Italian Studies Research}

In this context, it is worth highlighting some newer areas of research currently providing considerable impact, or with the potential to do so. A key area of enquiry in Italian Studies over the past decade involves post-colonialism and transnationalism, migration and diasporic studies, which combine research perspectives from across the social sciences, politics and the humanities, responding to 'real life' situations and linked to campaigns to tackle these major societal challenges. ${ }^{45}$ As has been noted by the director of the ESRC/AHRC Migration Leadership Team, Laura Hammond, 'the experiences of migrants have been captured through the arts and humanities - in literature, art and film; conveying migrants' experiences in unique and moving ways. Put them together and you have something that will really speak to a broader community; academics and even those who wouldn't normally read academic studies. ${ }^{46}$

Research projects in these fields have brought major opportunities for impact outside academia, as in the case of the multi-institutional AHRC-funded Transnationalizing Modern

\footnotetext{
${ }^{43}$ REF 2014 case study: <https://impact.ref.ac.uk/casestudies/CaseStudy.aspx ?Id=42282> [accessed 14 April 2019].

44 <http://ktp.innovateuk.org/> [accessed 23 January 2020].

45 The book series of Liverpool University Press Transnational Italian Cultures, edited by Emma Bond and Derek Duncan, was launched in 2016 to 'set a new agenda for academic research on [...] Italian culture today', focusing on postcolonial, global and transnational Italian studies.

46 Toby Shergold, 'New Migration Leadership Team will help academics speak to a broader community about migration' (08/01/2018), <https://ahrc.ukri.org/newsevents/news/new-migration-leadership-team-will-helpspeak-to-community/> [accessed 15 April 2019].
} 
Languages: Mobility, Identity and Translation in Modern Italian Cultures (2014-17). This pioneering project has examined 'the forms of mobility that have defined the development of modern Italian culture and its interactions with other cultures across the globe', focusing on a series of case studies representing 'the geographic, historical and linguistic map of Italian mobility'. ${ }^{47}$ Research and fieldwork have addressed narratives of recent migrants to Italy, multilingual repertoires of and translations for contemporary migrants to Italy, Italian diasporic cinema, the construction of identity and 'Italianness' in different media, memory archives, and the postcolonial legacy and cultures of second-generation Italians globally. The project has engaged a vast range of individuals and local communities, including policy makers, cultural associations and institutes worldwide (such as the Archivio Memorie Migranti in Rome), and experts from across the arts, which led to the creation of a touring exhibition (now accessible virtually). ${ }^{48}$ Links have also been made with schools and educational specialists, including from the University of Namibia, working on translation and education.

Further impact in related fields has been generated by informing and stimulating international debate on migration and the associated issues of racism and hate speech. Important work, based on linguistic research, has been undertaken with public organisations and NGOs such as NAGA in Milan and Amnesty International, in relation to the European elections of 2019. ${ }^{49}$ Additional impact activities include advising media professionals and engaging social activism. Different forms of social media and university radio have also been used to develop synergies between research, teaching and public dissemination. ${ }^{50}$ In the summer of 2019, an exhibition in London, linked to a recent publication and entitled 'Sink Without Trace', addressed migrant deaths at sea. ${ }^{51}$

As noted above, a number of research projects have used digital elements to encourage interdisciplinarity and to stimulate collaborations. Such tools have also enabled members of the public beyond academia to access research findings in different formats, with the potential to increase critical awareness and access online training. The prolific field of Dante studies has, in many ways, been a pioneer for specialised and educational digital

\footnotetext{
${ }^{47}$ For details of this project, funded by one of three large grants awarded under the AHRC's Translating Cultures scheme, see <https://www.transnationalmodernlanguages.ac.uk/about/project/> [accessed 15 April 2019].

48 The Exhibition 'Beyond Borders: Transnational Italy' (2016-17) was shown in London, New York, Melbourne and Addis Ababa, Rome. See <https://www.transnationalmodernlanguages.ac.uk/mediacollection/exhibition-beyond-borders-transnationalitaly/> [accessed 15 April 2019]. The research fed into the policy statements in the 2015 'London Statement' produced in the wake of the first biannual conference of the Cultural Literacy in Europe forum, in which project members participated.

${ }^{49}$ Federico Faloppa, 'Un anno di odio: dalle politiche 2018 alle europee 2019, in Amnesty International, Barometro dell'odio: Elezioni europee 2019

<https://d21zrvtkxtd6ae.cloudfront.net/public/uploads/2019/05/29202706/Amnesty-barometro-odio2019.pdf> [accessed 20 July 2019].

50 'Creating New Realities with Language' (July 2017), <https://www.reading.ac.uk/modern-languages-andeuropean-studies/ stories/mles-f-faloppa.aspx> [accessed 11 April 2019].

${ }^{51}$ Federica Mazzara, Reframing Migration: Lampedusa, Border Spectacle and Aesthetics of Subversion (Oxford: Peter Lang, 2019). On the exhibition (June-July 2019) and other events as part of the 'Language Acts and Worldmaking' OWRI project, see $<$ https:// www.languageacts.org/events/reframing-migration-lampedusaborder-spectacle-and-aesthetics-subversion/> [accessed 11 April 2019].
} 
projects, having created open access platforms since the early 1990s. ${ }^{52}$ These projects facilitate public access not only to Dante's text but also to scholarship drawing on the more traditional disciplines of textual interpretation and commentary, philology, history of the language, and manuscript and book history. They also incorporate newer approaches like material history and cross-disciplinary connections with the visual arts and music. Such digital projects, together with library digitisation projects using powerful visualisation tools, have been important in enabling open access to rare books and manuscripts from collections worldwide.

Another example of the use of digital elements in multi-disciplinary research is the AHRC funded Italian Cinema Audiences project (2013-16), involving a team of researchers with a variety of expertise (language, culture, economics, gender, geography, film, oral history, and memory studies) ${ }^{53}$ Because of the breadth of expertise, the team was able to contribute to research development across different areas, as well as propose an impact case that took into account the wide range of approaches used. The award of AHRC Follow-on Funding enabled the creation of the digital online archive CINERICORDI ${ }^{54}$ which integrated the previously collected data (questionnaires and video-interviews) with new and unexplored archival resources, including digitised artefacts related to cinema-going and crowd-sourced collections from individuals' private archives. The materials were gathered via an innovative methodology that enabled the participants involved to set the research agenda. As coinvestigator, the University of the Third Age (UNITRE) provided participants and coorganised public engagement events where research findings were presented to over a thousand of its members. Not only has this project raised public awareness and understanding of the importance of autobiographical memories for the elderly; it has also contributed to a process of re-writing audience history from below, thereby empowering its very protagonists.

Other projects have developed research databases which contribute to the development of library and information services and resources, and to cultural heritage preservation. This is the case with two projects from the early modern period. The Italian Academies: The First Intellectual Networks of Early Modern Europe (AHRC-funded 200609; 2010-14) developed among its research outputs the open-access, interactive Italian Academies Database, created with software specialists from the British Library and hosted on the Library's public website as part of its Themed Collections series. ${ }^{55}$ This allows users to explore virtually the eight hundred or so academies, or learned societies, which were formed over the peninsula between c. 1525 and 1700, and which were central to the development of new forms of culture and intellectual enquiry across the arts and sciences. Users can navigate links between academies, their members and books, based on information mined from close analysis of the British Library's unique collection of early Italian books, a collection that remains invisible to readers searching the main library catalogues. Over a thousand rare images from books and marginalia (including from books by Galileo Galilei) have also been digitised. Importantly, the database enhances public access to rare books, with impact on both cultural life and public services. The collaboration between academics and the British Library

\footnotetext{
${ }^{52}$ See, for example, the Digital Dante project (initially founded in the early 1990s and relaunched in 2014): <https://digitaldante. columbia.edu/>; and with $2.9 \mathrm{~K}$ Facebook followers and teacher resources:

$<$ http://www.worldofdante.org/about.html> [accessed 7 May 2019].

$53<w w w . i t a l i a n c i n e m a a u d i e n c e s . o r g>$ [accessed 20 July 2019].

$54<$ www.cinericordi.it> [accessed 20 July 2019].

55 <http://www.bl.uk/catalogues/ItalianAcademies/> [accessed 20 July 2019].
} 
also led to the material improvement of the methods and software used by library and information professionals. The recent archiving of the raw data (8,598 records) by the library as part of their open-access agenda enables the continued process of knowledge transfer within larger international forums.

A more recent project, Petrarch Commentary and Exegesis in Renaissance Italy, $c$. 1350-c. 1650 (AHRC-funded, 2017-19), similarly has at its core a freely accessible, searchable database, which establishes the research field. ${ }^{56}$ This provides information on a substantial corpus of Italian commentaries (produced in print and manuscript) on the vernacular works of Petrarch, which were seminal within European culture but open to enormously diverse kinds of interpretation over the period examined. The database therefore provides a census for exploring the changing forms and subject matter of exegesis and commentary, and for how this tradition influenced writing practices and reflected broader developments in Renaissance print culture. The full impact of the project will be better assessed after its completion, but its digitisation of around one hundred works held in the John Rylands Library, University of Manchester and of fourteen further digital editions of works from the Hesburgh Library at the University of Notre Dame will enhance public access to these resources. The project also connects with broader interests in reception studies beyond the peninsula and with textual diasporas - the subject of other impactful research projects and networks involving Italian collaborations. For instance, the Diasporic Literary Archives Project (Leverhulme funded, 2012-15) has created an international network involving partners from the UK (University of Reading), the Centro per gli studi sulla tradizione manoscritta di autori moderni e contemporanei at the University of Pavia, alongside others in France and Trinidad and Tobago, with the aim of promoting the preservation of literary archives and access to them. This involves as stakeholders librarians and archivists, authors, agents, manuscript dealers, and bodies like the Society of Authors and UNESCO. ${ }^{57}$

A number of projects have involved productive collaborations with museums, galleries, archives and other related institutions in the UK, again with the aim of enhancing and preserving heritage or bringing new research perspectives to existing collections. The ERC-funded project Domestic Devotions: The Place of Piety in the Italian Renaissance Home (2013-17) curated an innovative exhibition on Madonnas \& Miracles: The Holy Home in Renaissance Italy (2017), in collaboration with the Fitzwilliam Museum in Cambridge. This was an integral part of the research and fieldwork within the fields of literature, architecture and history of art, and history. It demonstrated the key role of religion and spirituality for the laity in the period 1400-1600, challenging the popular idea of the Renaissance as an age of growing secularism. It also explored the domestic sphere through books, buildings, objects, spaces and archives, also from less known centres across Italy. The exhibition was visited by around fifty thousand people and can still be referred to through the associated catalogue and website. ${ }^{58}$ Other research undertaken in collaboration with the

\footnotetext{
$56<$ https://warwick.ac.uk/fac/arts/ren/researchcurrent/petrarch/>; Petrarch Exegesis in Renaissance Italy Database (PERI) is available at <https://petrarch.mml.ox.ac.uk/node/188> [accessed 15 May 2019].

${ }^{57}$ See <http://www.diasporicarchives.com/> [accessed 16 April 2019].

${ }^{58}$ Madonnas \& Miracles: The Holy Home in Renaissance Italy, ed. by Maya Corry, Deborah Howard and Mary Laven (London: Philip Wilson, 2017); see <http://www.fitzmuseum.cam.ac.uk/madonnasandmiracles $>$ [accessed 26 April 2019].
} 
National Trust has addressed collections of Italian books in English great house libraries and the influence of the Grand Tour (with exhibitions at Belton House, Lincolnshire in 2013 and Audley End, Essex, in 2019). The exhibition encourages visitors 'to consider the role of books in the life of an important household and how libraries are repositories of the social history of a place and its wider cultural encounters' ${ }^{59}$ Furthermore, as part of the AHRCfunded project Mapping Literary Space: Intellectuals, Journals, and Publishing Firms in Italy 1940-1960 (2012-15), exhibitions of special collections of author and publisher archives were held at the Museum of English Rural Life in Reading (2014) and the Anthony Burgess Foundation in Manchester (2014). These developed and documented research on Italian periodical publications and their transnational reach.

Another very different kind of methodology which has more recently emerged in a series of impactful projects within Italian Studies is linked to performance of various kinds. As noted already, musical and theatre performances or spectacle have played a significant part in various forms of collaboration, involving groups from professionals through to schoolchildren. These can inform educational practices (including language instruction) and bring important new perspectives to bear on research, for example through historical reconstructions and performer or audience involvement and feedback. This is the case with the above-mentioned work of Musica secreta, which specialises in music associated with highly gifted women from Italian Renaissance courts and convents. Associated research on musical culture and practical investigation has here informed performance practices of early music groups.$^{60}$ Presentations and performances across different media have concurrently helped to challenge dominant narratives about the extent of women's participation in musical life in Renaissance Italy. Similar collaborations involving professionals and amateurs have underpinned other research-based public performance events in this field (e.g., on Early Modern Venetian Lute Music and Dance, and on the Virtuosa Singer in the Academies of Early Modern Italy), further generating public interest. ${ }^{61}$ The first-ever performance of a recently discovered manuscript play by a practically unknown Renaissance noblewoman from Lucca active in Medici spheres (Leonora Bernardi) took place in May 2018, involving NYU students, theatre professionals and academics. The play highlights female protagonism and pro-feminism in the period. ${ }^{62}$ Other significant cross-period research projects on Italian divas, cinema, theatre and opera audiences and producers promise further exciting opportunities for testing research in practice and generating potential future impact, as do the results of the pioneering cross-disciplinary ERC-funded project Italian Voices: Oral Culture, Manuscript and Print in Early Modern Italy, 1450-1700 (2011-2015), which reconstructs soundscapes and audiences.

\section{Future Opportunities for Developing Research Impact}

\footnotetext{
${ }^{59}$ See <https://www.cam.ac.uk/research/features/an-enchantment-with-italy-one-family-and-their-books> [accessed 25 April 2019].

60 <https://musicasecreta.com/>[accessed25April2019]; Laurie Stras, Women and Music in Sixteenth-Century Ferrara (Cambridge: Cambridge University Press, 2018).

${ }^{61} \mathrm{See}<$ https://www.kcl.ac.uk/artshums/ahri/eventrecords/2017-2018/cems/early-modern-venetian-evening-lutemusic-anddance> (event held 13, February 2018); and <https://www.ucl.ac.uk/earlymodern/events/2018/sep/virtuosa-singer-academies-early-modern-italy> (event held 17 September 2018). ${ }^{62}$ A video of the live performance in May 2018 at Villa La Pietra, NYU Florence of Clorilli: A Pastoral Drama by Leonora Bernardi of Lucca (1559-1617) can be seen at 〈https://www.youtube.com/watch?v=sCCf8al5Sw0> [accessed 15 April 2019].
} 
As the examples discussed suggest, it is clear that research on subjects from any period can engage public audiences and, in some cases, generate transformative impact. While some areas such as migration studies seem unlikely to disappear from the public agenda, others look poised to emerge more strongly in the future. There is scope for further developments to involve local communities and different publics, for example through collaborative research projects straddling the arts and sciences, which promote wider dissemination of scholarship and contribute to social belonging and well-being.

Emerging research in the environmental humanities and ecocriticism is one such likely area for future impact. The development of ecocinema, especially in Italy and in United States, has been showcased through film festivals and is gaining ground in comparative literature and other language area studies (most notably French). ${ }^{63}$ The medical humanities similarly present an exciting area for involving Italian Studies. Projects might, for example, explore the benefits and potential challenges of using literature and the arts to ameliorate the lived experience of illness or mourning. Poetry and Film in Palliative Care is a qualitative study that brings academics together with two Hospices in Edinburgh to examine the feasibility and acceptability of poetry reading and discussion with patients in palliative day care units, and to assess the benefits of film watching and discussion for the bereaved. ${ }^{64}$ Research in disability studies similarly promises substantial impact, for example in relation to 'understanding technologically-driven futures of disability experience'; and, as noted, work has already taken place to engage the elderly with online cultural heritage while bridging the digital divide, through the close collaboration between the Italian Cinema Audiences project and the University of the Third Age in Italy. ${ }^{65}$ Renaissance Skin (funded by the Wellcome Trust, 2016-21) explores the wide-ranging uses and conceptualisations of skin, both animal and human, in early modern Europe, aiming among other things to 'break down the divide between the study of human and animal skin diseases'. ${ }^{66}$ Such projects show the breadth of application of Italian Studies as broadly conceived, though the specific contribution of this discipline may not always be easy to trace in the outcomes. This issues raises longer term considerations about attribution in impact assessment and evaluation.

A further urgent case for continued impact regards the preservation of Italian heritage - not only in Italy, but also in unexpected places in the UK and worldwide. Digitisation presents new opportunities and has become notably easier, with the opening up of Italian State Archives to private photography. However, this is not the case for all archives and pressures in terms of staff resource and limited opening hours can still make research difficult. New platforms are beginning to emerge, where archival material is digitised,

\footnotetext{
${ }^{63}$ See, for instance Italy and the Environmental Humanities: Landscapes, Natures, Ecologies, ed. by Serenella Iovino, Enrico Cesaretti and Elena Past (University of Virginia Press, 2018); Monica Seger, Landscapes in Between: Environmental Change in Modern Italian Literature and Film (Toronto: Toronto University Press, 2015).

$64<$ https://poetryfilmcare.wp.st-andrews.ac.uk/about/> [accessed 19 April 2019]. Fascinating comparative arts/science impact projects were presented by artist Zoe Papadopoulou at the seminar on 'Mourning Between Life and Literature' (19 February 2019), together with Italian contributions: <https://www.ucl.ac.uk/institute-ofadvanced-studies/events/2019/feb/mourningbetween-life-and-literature> [accessed 19 April 2019].

${ }^{65}$ See the research project Imagining Technology for Disability Futures (2017-25), which brings together methodologies from the arts and humanities (including Italian Studies), product design and engineering/robotics, attracting funding from both the Wellcome Trust and British Academy: <https://ahc.leeds.ac.uk/dirrecord/research-projects/1209/imagining-technologies-fordisability-futures> [accessed 13 May 2019]. ${ }^{66}$ See <https://renaissanceskin.ac.uk/> [accessed 15 May 2019].
} 
catalogued and offered to researchers, as well as potentially to the general public, sometimes in the form of interactive databases and enhanced by digital tools. There are also research projects where the material digitised has been collected from several archives under a specific theme or area of interest, thereby unifying scattered sources. Such resources present vital pathways to impact which will benefit future researchers of all levels, together with the general public. Provided they are maintained and open to data-sharing - considerations which are not necessarily straight-forward - they can avoid replicating fieldwork or desktop research, thereby limiting costs of time, travel and so on to individuals (and institutions), and reduce environmental costs and potential damage to the original material heritage.

A prime example of the success and impact of the digitisation process is the PRINfunded project I cattolici e il cinema in Italia tra gli anni ' 40 e gli anni ' 70 (2012-16). ${ }^{67}$ This offers access to a wide range of documents (some up to now unpublished and unavailable to the general public) originating from private and public archives, with the intention of promoting studies on the role of Italian cinema in the negotiation processes of religious and social conflicts in Italy between the 1940s and the 1970s, a period strongly marked by transition in all areas of social life. A similar project (also funded by PRIN, 2017-20) is Comizi d'amore: Il cinema e la questione sessuale in Italia (1948-1978), which again brings together archival documents and newspaper and magazine articles related to the role of sexuality in Italian cinema. ${ }^{68}$ Both projects are excellent examples of how access to unexplored archives can be effected by research involving the creation of a database and effective collaboration with public and private institutions. These projects have the potential to provide the general public with new access to existing collections and generate significant impact beyond the academic community.

The Medici Archive Project, the digital platform (BIA) of which has been funded by Mellon since the early 1990s, provides another outstanding example of the way in which digital resources have promoted widening forms of impact through collaborative and innovative research. In this case, the mission has been 'to merge archival research with technological innovations for data management' by cataloguing the over four million letters of the Medici Granducal Archival Collection (Mediceo del Principato, 1537-1743), which documents all aspects of early modern Tuscany and Europe. The cataloguing was initially carried out for and by a restricted academic audience, with the support of NEH-funded fellowships. However, the project has increasingly become an international 'research institution with the mission of actively generating scholarly discourse and embracing disparate dimensions of scholarly experience'. It enables virtual discussions (with over 2,400 registered users of BIA) and, more broadly, in situ provision of archival training, publicly accessible workshops and conferences, in addition to publications. ${ }^{69}$ The new planned digital platform (MIA) promises a far richer collection of documents and innovative methods of data-entry.

While collaboration with public archives may be difficult, a very profitable and impactful activity is opening up to crowd-sourcing initiatives. The above-mentioned CINERICORDI archive project has made use of this modality, resulting in the creation of a

\footnotetext{
67 <http://users.unimi.it/cattoliciecinema/home/> [accessed 2 May 2019].

$68<\mathrm{https} / / /$ sites.unimi.it/comizidamore/> [accessed 2 May 2019].

${ }^{69}$ See the Medici Archive Project (MAP) mission statement: <http://www.medici.org/mission/> [accessed 14 April 2019].
} 
database that started with over three hundred documents (film posters, images, film programmes, etc.) and is now gradually expanding thanks to the regular contribution of the general public, interested in sharing their personal collections. This process enables new research discoveries while producing a significant impact on local communities. The CINERICORDI project, for example, has encouraged the general public to engage with their local history and several initiatives have emerged as a consequence; these include a book written by one of the participants on the history of the cinemas in Amelia, ${ }^{70}$ and an exhibition in Manduria on film posters and the life of local exhibitors. ${ }^{71}$

Alongside schools, universities, libraries and archives, other avenues and venues for impact include: media coverage of research projects (both in academic-related publications such as the TLS and The Conversation, and in the local and national press); and close collaboration with cultural institutions (such as the Italian Cultural Institute; Il Circolo; British-Italian Society; London Film Institute; Glasgow Film Festival) and professional societies, such as the British Film Society. The Press Play Conference that took place at the British School at Rome in 2019 provided an important forum for addressing the relationship between the arts, research and public engagement. ${ }^{72}$ Taking the form of a workshop with interventions by academic speakers and art practitioners, this event facilitated collaboration between artists, the research community and the British School. Grounding the conversation in the broad disciplinary area of modern languages, it explored common interests in creativity in, and as, research practice. Another obvious pathway for generating impact is via public events, festivals and celebrations including the active contribution of universities and research centres. The Festival of Italian Literature in London, launched in 2017 as a response to the Brexit referendum, has already successfully established itself as an important platform for innovative cultural engagement and partnerships between academia, business, journalists and public bodies, including the Italian Cultural Institute. ${ }^{73}$ Universities and research centres have also embraced this kind of public engagement, including the Leeds Centre for Dante Studies, which organised events involving Opera North and the Choir of Leeds Cathedral, in addition to public lectures made available via podcast. Anniversaries form important opportunities for public engagement too. For instance, 2016 marked the five-hundred-year anniversary of the publication of Ariosto's Orlando furioso. Academics contributed to a series of public events round the world, including readings of the poem (Italy Radio 3), exhibitions, and occasions which also involved popular actors and singers. In Italy, these were led by a specially founded Comitato Nazionale per le Celebrazioni del V centenario dell'Orlando furioso. These events promoted the relevance of Ariosto's work internationally, for example, its interest in issues of religion and language, and its adaptation and visual reception for public audiences. ${ }^{74}$ The Leonardo da Vinci (2019) and Dante (2021) anniversaries, present similar opportunities.

\section{Conclusions: Benefits and Challenges of the Impact Agenda in Italian Studies}

\footnotetext{
${ }^{70}$ Mara Quadraccia and Nino Rinaldi, Amelia, Perla del cinema (Terni: Umbria Volontariato Edizioni, 2019).

71 'Il cine-teatro a Manduria nel '900', 20 October 2018, Cinema Candeloro, Manduria, Puglia.

72 <http://www.bsr.ac.uk/press-play-creative-interventions-in-research-and-practice> [accessed 29 April 2019].

${ }^{73}$ See $<$ https://www.fill.org.uk/about/ $>$ [accessed 4 October 2019].

${ }^{74}$ Stefano Jossa, 'Ariosto Redivivus in 2016: A Year of Centenary Celebration and Critical Reassessment of Orlando furioso', The Italianist, 38.1 (2018), 134-49.
} 
Italian studies, with its multiple disciplines and language-based intercultural approaches, has clearly engaged in the impact agenda in very diverse and imaginative ways. This has increasingly influenced the shaping and methodologies of research and effected shifts in communicative approaches. In the UK, the public funding situation and the demands of HEIs now mean that pathways to impact are often built into projects from the outset in order to ensure the visibility of research and the communication of its relevance and its contribution to societal needs, interests, and cultural diversity. With students in several institutions being required to include some sort of impact activity or 'connected curriculum' engaging with non-academic stakeholders during their studies, this expectation is likely to increase. Given the challenges that lie ahead, in terms of student recruitment for modern languages and growing competition in language-based cultural studies from comparative literature and culture in translation, such approaches will be vital for the future positioning of the discipline and its capacity to engage a wider community. This involves reaching new audiences not only across the age spectrum but also across wider geographical areas. ${ }^{75}$ The current situation suggests there is a continuing need to create regional disciplinary hubs, headed by universities, but ideally including other private and public sector bodies and charities, and leveraging Italian representation (native or heritage) to concentrate resources locally and counter the predominance of large metropolitan cities, while also building international collaborations. ${ }^{76}$

The viability of Italian Studies (and Modern Languages) will depend, on the one hand, on demonstrating impact at discipline-level in areas that are currently privileged and recognised. For example, impact from Italian Studies clearly aligns with existing criteria in its engagement with stakeholders from the heritage industry, the media and publishing industries, legal and political bodies (including NGOs and policy makers), museums and libraries, and health providers - though collaborations and events or outputs in themselves will not guarantee 'impact' in the narrow REF sense. There is also great potential in Italian Studies for further co-operation with commercial sectors, including tourism, technologies with financial applications (including artificial intelligence), and the creative industries, which have recently attracted significant government funding and which could facilitate more easily evidenced and quantifiable impact for certain types of research in the discipline.

For Italian Studies to be recognised as having value in the economised terms of research policy makers in the UK, it is crucial to gather metrics relating to outcomes for the discipline - which currently remains invisible in the REF Units of Assessment. Research funding in the UK (from UKRI) is currently linked to the qualitative and measurable nature of the impact generated from research. The tendency is towards ever increasing datagathering. However, it is based on a system of metrics which is not uniform across the relevant platforms (REF, Researchfish and others), and which is designed for the hard sciences and economic ends; as a result, the system may be incompatible with and unable to recognise the value due to different forms of research impact in the arts and humanities. For this reason, case studies have been acknowledged as being more useful in terms of

\footnotetext{
75 The British Council 'Language Trends 2018' report specifically mentions schools with reduced access to languages in the North of England, most notably in Yorkshire, the Humber and the North West, pp. 5,6: <https://www.britishcouncil.org/sites/default/files/language_trends_2018_report.pdf> [accessed 26 June 2019]. ${ }^{76}$ A good example is LivItaly: Bringing Italian culture to Yorkshire, University of Leeds (2012-); see<https://ahc.leeds.ac.uk/livitalybringing-italian-culture-yorkshire> [accessed 20 July 2019].
} 
understanding in detail the pathways and depth of the contributions of the arts and humanities. ${ }^{77}$

On the other hand, continued influencing of policy making to protect, value and enable the study of modern languages will also be crucial. This will involve communicating effectively the associated benefits of Italian Studies research and articulating a different understanding of research, one that counters instrumentality and recognises the intrinsic value and the significance of the processes the research stimulates. Informal interactions between academic researchers and parliamentarians can be valuable in this respect, such as via the 'All-Party Groups' (APGs) of UK parliamentarians: of which there are ones concerned with modern languages and Italy. Soberingly, there is not one specifically concerned with the arts and humanities, though several meet to discuss scientific and technological matters, and others exist for Social Science and Policy, arts and heritage, archives and history, and archaeology ${ }^{78}$ As for the arts and humanities in general, it is important to articulate how research in Italian Studies has demonstrated a capacity to enrich cultural lives, inform public debate, and foster critical reflection and innovation by contributing a unique perspective to distinct specialisms. ${ }^{79}$

Public and social media communication via institutional forums may well form part of planned 'pathways to impact' in a research project, but individual academics can also make significant impact by responding to events or reporting new related finds as they arise, in blogs/social media or occasional writings and media appearances. The fact that research may gain particular public relief and significance in light of social and political concerns (postBrexit uncertainties, migrant tragedies, the rise of anti-democratic and far-right movements, the \#MeToo movement, and feminist and LBGQT agendas) demonstrates the unpredictable, contingent, and serendipitous aspect to impact in various cases. Such participation places very different demands on the researcher from planned academic outputs, in terms of communication style, speed of response and flexibility, and concision. As when writing for commercial presses, authors are admired for their spare, punchy writing, their ability to grip audiences with vivid stories, and for combining clarity and academic rigour. ${ }^{80}$ However, understanding the best communication routes and developing appropriate styles takes time and effort, and often specific media training and close collaboration with professional editors, film crews and so on. Such issues will increasingly need to be taken into account both for researchers and institutions, in terms of incentivisation to media engagement, provision of training opportunities and the allocation of resources for 'impact' outputs alongside research - and their recognition afterwards.

One decade into the emerging impact agenda there is clearly much to be gained by increased sharing of ideas and good practice in planning 'knowledge translation' and implementing data collection, as well as experiences and contacts of working with different stakeholders, and with interdisciplinary collaborations. Within universities there will be benefits to merging fields of specialism across the humanities, arts and sciences, and IT/Library services, and strengthening cross-Faculty collaborations. The sometimes-patchy

\footnotetext{
${ }^{77}$ Cope, p. 11; The Nature, Scale and Beneficiaries of Research Impact, p. 59.

${ }^{78}$ Cope, p. 8.

${ }^{79}$ Bulaitis, pp. 5-7.

${ }^{80}$ See Edmund Prestwich's review of Prue Shaw's Reading Dante, From Here to Eternity (March 2015) $<$ http://www.themanches terreview.co.uk/?p=4576> [accessed 22 April 2019].
} 
provision of IT resources will also need addressing, since there are risks and difficulties in working with external providers. The question of administrative resourcing may prove beneficial to review as the costs of impact activities to staff time become more recognised. Within the wider Italian Studies community too - beyond the 'Modern Languages' boundary - there is scope for reflection and discussion. Subject association conferences could, for instance, benefit from dedicating regular sessions to research impact, including contributions from stakeholders external to academia (as in the recent British Academy workshop and the Society of Italian Studies Biennial conference in Edinburgh in June 2019 which included writers Jhumpa Lahiri and Igiaba Scego among the keynote speakers). This would amount to a concerted approach to impact at discipline level and facilitate dissemination and reporting.

To conclude, the impact agenda, both as a by-product of research dissemination and as a means of generating new findings and collaborations, is not likely to disappear in the foreseeable future. Rather, it is likely to increase in accordance with a growing imperative to provide 'accountability for public investment in research and [produce] evidence of the benefits of this investment'. ${ }^{81}$ This begs the question of how the impact agenda will in future affect 'curiosity-driven' forms of academic research aimed principally at a specialised audience and unlikely to have an immediately discernible 'impact' at the outset. Currently, in the UK research funding allocations (from REF) are still overwhelmingly based on the quality of each institution's research outputs $(60 \%)$, assessed in terms of 'originality, significance and rigour', with reference to international standards. In this regard there is still a place for the lone scholar, for specialised monographs with academic presses, as well as for research that builds on well-established methodologies, or for research involving more creative or speculative, blue-sky thinking. The challenge within Italian Studies and the humanities more broadly (and for some scientific disciplines) will be to demonstrate how specialist 'pure' research benefits publics, even if less directly, and to argue for its reputational and intrinsic value in tackling complex subjects which may be less open to wider 'translation'. This is essential given that the drive in academia and among UK funding councils seems irrevocably towards a parallel communication of research findings for audiences beyond academia and globally. Public funding is increasingly skewing the balance towards particular kinds of research that fit the criteria for tangible benefits and measurable outcomes. In order for Italian Studies to continue to thrive at an international level, researchers within the discipline will be encouraged to embrace opportunities for public engagement where they arise, and to seek pathways to impact - just as a new generation of researchers are being expected to do.

The impact agenda demands due caution, preparedness and a sense of purpose, so it is more than a 'going through the motions'; it also requires realistic costing on the part of individuals and institutions, and broader reflection on the value of research. Impact may not and need not - be something for everyone within Italian Studies, but a readiness to identify the intrinsic interest in and need for the valuable research generated by the community will be key to the continued flourishing of the discipline, which has much to offer society as a whole.

Disclosure statement

\footnotetext{
${ }^{81}$ This is one of the three identified purposes of REF2021 <https://www.ref.ac.uk/media/1016/draft-guidanceon-submissions-ref2018_1.pdf> [accessed 20 July 2019], p. 8.
} 
No potential conflict of interest was reported by the authors. 